\title{
Identification and Exploration of the Needs for Health Care among Initial Defaulters of Tuberculosis Treatment in Selected Areas, Puducherry, Approved by Tuberculosis Association of India
}

\author{
Jayaraman Bamalakshmi ${ }^{1}$, Venkataraman Subakeerthi ${ }^{2}$, Kandasamy Renuka ${ }^{3}$
}

\begin{abstract}
Background: In India, around 1.98 million cases of tuberculosis (TB) during 2015, representing one-fifth of the global incidence. The initial default is a potential complicating issue, particularly in cases of smear-positive patients because they may continue spreading the disease. The purpose of the study to identify and explore needs required among initial defaulters during TB treatment by using descriptive, exploratory design.

Materials and methods: Qualitative exploratory approach, descriptive design, and purposive sampling technique adopted among 29 initial defaulters of TB treatment from the lab register in chest clinic, Puducherry. In this study, a structured interview schedule was used to assess the selected demographic variables, and an open-ended questionnaire was used to identify the factors influencing initial defaulters of TB treatment. Results: The result reveals that there is a significant association $(p<0.05)$ found in selected demographic characteristics like age, gender, educational status and occupation, type of family, and family history of TB with a minimum duration of 2 years among initial defaulters of TB treatment.

Conclusion: The result of this study shows that there is a need on exploring the health needs among the majority of the initial defaulters need regarding awareness on treatment of TB including defaulters and initial defaulters, enforcing to know the importance of completing the course of treatment, 17 of them were asking facilities like cycle and slippers as well as access of drug through the health workers.

Keywords: Identification and exploration of the needs for health care, Initial defaulters, Tuberculosis treatment.

Pondicherry Journal of Nursing (2020): 10.5005/jp-journals-10084-12171
\end{abstract}

\section{INTRODUCTION}

Tuberculosis (TB) is a contagious disease caused by Mycobacterium tuberculosis (MTB) which commonly affects the lungs and other parts of the body, such as, lymph glands, bones, joints, skin, intestine, and meninges. The bulk of infectious diseases are known as latent TB. If left untreated of latent infections progress to active disease which kills about half of those infected. Chronic cough with blood-containing sputum, fever, night sweats, and weight loss are classic symptoms of active TB and other organs also infected which cause a wide range of symptoms. Tuberculosis is an airborne disease so which spreads from an infected person to a non-infected person through cough, spit, speak, or sneeze but during the latent period the infection will not spread. When the infection affects the entire lungs causes the pulmonary TB event which affects other parts of the body. HIV/AIDS patients are more vulnerable to secondary infection of TB. Accurately TB infectious disease determined by chest X-rays, microscopic examination, and sputum culture. ${ }^{1}$

One-third of the TB infected population worldwide and $1 \%$ of the population in every year. ${ }^{2}$ Active cases of TB occurred around 9.6 million in 2014, contributing to 1.5 million fatalities. Tuberculosis is among the top 10 causes of global mortality. ${ }^{3}$ The causative organism was discovered 100 years ago, TB remains a global public health epidemic in the current situation available effective drugs and vaccines for the treatment of the TB. ${ }^{4}$ In many countries, there is drug resistance cases are high even with the national TB control program and after the introduction of short-course chemotherapy. The causes are poverty, economic crisis, hunger, overcrowding,

\footnotetext{
1,2 Department of Community Health Nursing, Kasturba Gandhi Nursing College, Puducherry, India

${ }^{3}$ Department of Medical Surgical Nursing, Kasturba Gandhi Nursing College, Puducherry, India
}

Corresponding Author: Jayaraman Bamalakshmi, Department of Community Health Nursing, Kasturba Gandhi Nursing College, Puducherry, India, Phone: +91 9659366979, e-mail: bamalakshmiv@ kgnc.ac.in

How to cite this article: Bamalakshmi J, Subakeerthi V, Renuka K. Identification and Exploration of the Needs for Health Care among Initial Defaulters of Tuberculosis Treatment in Selected Areas, Puducherry, Approved by Tuberculosis Association of India. Pon J Nurs 2020;13(4):82-85.

Source of support: Extra Mural Research Fund Approved by Tuberculosis Association of India.

Conflict of interest: None

pollution of indoor air, tobacco, misuse of alcohol, diabetes, and HIV patients are more vulnerable groups for TB. ${ }^{5}$ Around one-third of India is with a burden of TB about 22 lakh new cases, 10 lakh smearpositive with highly infectious cases, and 500,000 people die from TB each year, more than 1,000, every day, one in every minute. ${ }^{6}$

In India, Revised National Tuberculosis Control Program (RNTCP) was initiated for TB treatment by providing free of cost in India through a network of designated microscopy centers (DMCs) and monitored by direct observed therapy (DOT) centers. All diagnosed TB patients are initiated into care by the health facility nearest to all 
positive TB patients within 7 days after the confirmation. Feedback is given to the DMC as soon as the patient initiates treatment, and this is recorded in the RNTCP Laboratory Registry. Initial defaulters are counted at the level of the district and are reported to the state and central units every quarter. They are not included in the RNTCP quarterly cohort reports on case results and treatment outcomes, as they are neither initiated into RNTCP treatment nor reported in the RNTCP TB registers. ${ }^{7}$ To ensure the effectiveness of the TB control program, RNTCP tracks the continuation of care for all diagnosed smear-positive cases of pulmonary TB. ${ }^{8}$

\section{Need for the Study}

Each year about 8 billion people worldwide are infected with MTB and 1.87 million die, $30 \%$ of the burden of TB, and $85 / 100,000$ new cases of smear estimated by WHO. ${ }^{9}$ During the 1960s, India introduced a National Tuberculosis Program (NTP) expansion to tackle TB after expert reviews conducted by the Indian government suggested that shortages of medicines, insufficient staff, and weak patient follow-up were $<30 \%$ of patients enrolled in the completed course of treatment as well as established reasons for inappropriate completion of the course of treatment. In 1993, the WHO integrated NTP recommended Directly Observed Treatment Short-Course (DOTS) has a global plan and conversion of NTP has a "Revised National Tuberculosis Control Program (RNTCP)".10

Different research studies related to TB revealed that travel expenses, traveling to treatment centers and the key determinants of the initial default of TB care are male sex, inadequate patient data and communication, alcoholism, and homelessness. Using the DOTS strategy with a targeted cure of $85 \%$, the government launched a TB eradication program. However, DOTS coverage is only $14 \%$ with a high number of initial defaulters as the obstacle. ${ }^{11}$

It is easy to calculate the initial defaults of smear-positive cases as the results and address or origin of the samples are reported in the laboratory register. As the disease continues to be transmitted, initial failure is a potentially serious problem, especially in smearpositive patients, so various activities are initiated to control the rates of initial defaulters. ${ }^{12}$

Several studies related to TB treatment revealed the importance of reducing the obstacle in the initiation of treatment. A study conducted in the district of Tiruvallur recorded an initial default rate of $29 \%$ among patients in a community survey, compared to $15 \%$ among those attending government health facilities because of lack of knowledge of initial defaulters and their severity.

There is a $79 \%$ cure rate of new sputum smear-positive (NSP) TB in the Darjeeling district, which is below the target amount. The initiation of treatment may be one of the factors of epidemiological importance. In West Bengal, the highest case finding and death rate $(326 / 100,000)$ is strongly transmitted and late case detection in geographically complex terrain with a lot of difficulties reaching the target areas. Due to a high failure rate (11\%) of 12 Cat II patients and multidrug-resistant (MDR) TB, RNTCP in West Bengal (December 2004) was one of the first districts to launch DOTS plus. DOTS plus was launched in October 2009 in the Darjeeling district. Thus, the district regarding initiation of treatment for initial default still unfolded. ${ }^{13}$

The initial default is a potentially serious problem, particularly in cases of smear-positive patients because they continue transmitting the disease. This is again regrettable that this is still highly prevalent in our society. This finding helps the investigator in identifying and exploring appropriate measures to control recommendations to initial defaulters for continuing TB treatment. ${ }^{14,15}$

\section{Statement of the Problem}

"Identification and Exploration of the needs for Health Care among Initial Defaulters of Tuberculosis Treatment in selected areas, Puducherry."

\section{Objective of the Study}

To identify and explore the needs for health care among initial defaulters of tuberculosis treatment.

\section{HyPOTHESIS}

$\mathrm{H}_{1}$ : There is an association between the initial defaulters of TB treatment and their selected demographic variables.

\section{Materials and Methods}

The study was carried out by retrospective examination of data from the Laboratory Registry TB Chest Clinic in giving a period of 2015 IV Quarterly to 2016 Quarterly_I, II, and III reports registered in Puducherry. The research design used for this study was a descriptive, explorative survey design. The study sample comprised of 29 initial defaulters among new sputum-positive TB patients diagnosed during the 1 year (2015 Quarterly_IV to 2016 Quarterly_I, II, and III) selected using the purposive sampling technique and who met the inclusion criteria and those who were willing to participate. The purpose of the study was to identify and explore the health care needs among initial TB treatment defaulters with the use of a structured interview schedule. The inclusion criteria are initial defaulters registered in Puducherry and those who are willing to participate. The tools used for this study consisted of two parts which are

- Part I: Background characteristics.

- Part II: Open-ended questions related to identification and exploration of the needs for health care among initial defaulters of TB treatment (Flowchart 1).

\section{Results}

Initial defaulters were in the age group of $41-60$ years, 18 (62.0\%). In the majority of the subjects, 23 (79.3\%) were male. Among the subjects, 14 (48.2\%) belong to Muslims. Eleven (38.9\%) of the subjects were illiterate. In the majority of the initial defaulters, 18 (62.0\%) were unemployed and 15 (51.7\%) were getting their monthly family income Rs. 5001-10,000 per month. In the majority of the subjects, 21 (72.4\%) were from joint family. Eight (27.5\%) of the subject were had a family history of TB for 2 years. In all the subjects, $29(100 \%)$ were having a source of knowledge on TB through mass media 20 (68.9\%) and 9 (31.0\%) were from health professionals.

\section{Discussion}

This study revealed that exploring the needs for health care among initial defaulters of TB treatment was 08 (27.5\%) of the subjects' need regarding awareness on prevention and control of TB including defaulters and initial defaulters. Twelve $(41.3 \%)$ of the subjects enforcing to know about how the importance of complete the course of treatment. Sixteen (51.7\%) of initial defaulters were asking 
Flowchart 1: Schematic representation of the study methodology

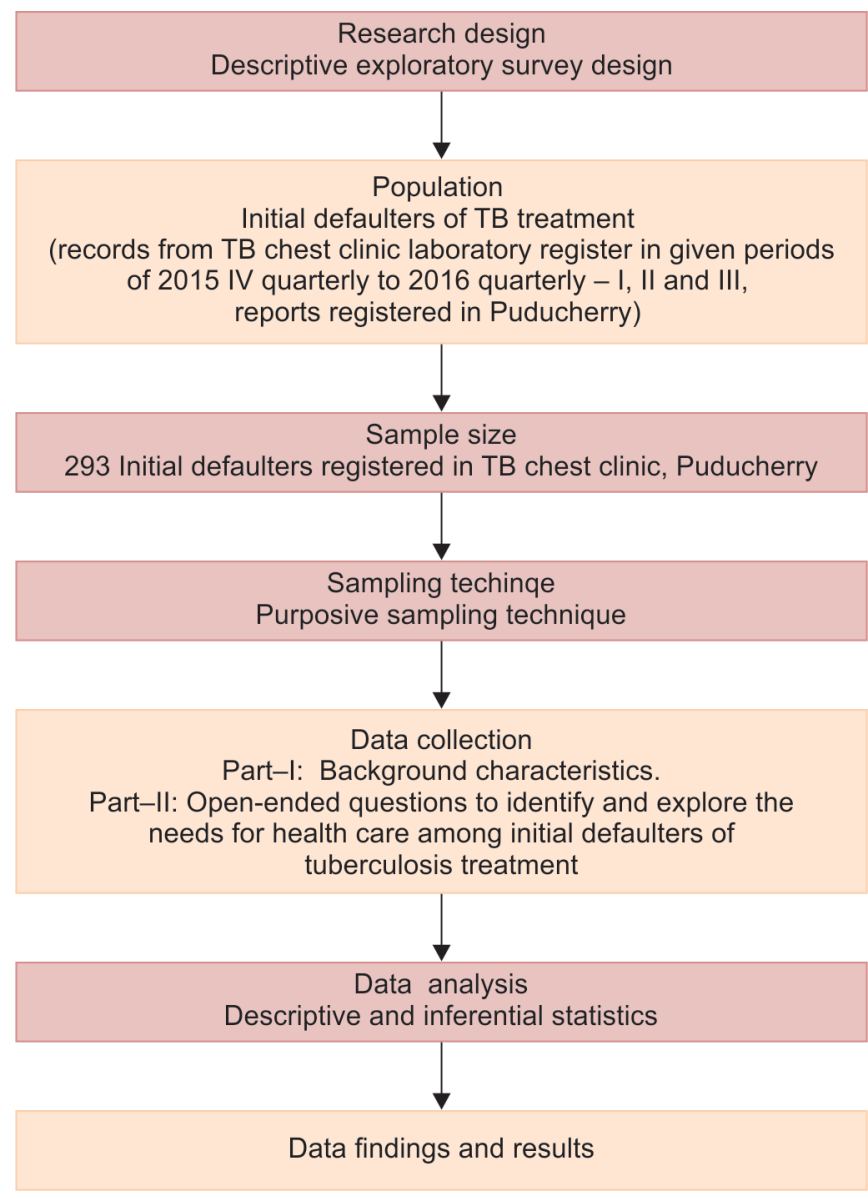

for facilities like cycle and slippers as well as access to the drug through the health workers. Most of the subject 21 (72.4\%) need de-addiction service along with TB treatment including nutritional kits, such as, pulses and eggs (monthly 15 eggs), 7 (25.0\%) of the subjects asking SMS alert for regular drug therapy, 22 (75.8\%) of the initial defaulter's needs on family motivation and counseling service, $24(82.7 \%)$ of them expecting from their family support toward TB treatment.

These findings are supported by DivijaPillai et al. ${ }^{16}$ conducted a study on the initial default among newly diagnosed TB patients. Problems and most of the explanations found in this analysis for initial defaulters and due to long-term course of therapy, not access to transport facilities and very higher rates of initial defaulters were due to lack of family support (Table 1 ).

\section{Conclusion}

From this study, the researcher concludes that there is a need on exploring the health care needs among initial defaulters on need regarding awareness of prevention and control of TB including defaulters and initial defaulters, enforcing to know about how the importance of complete the course of treatment, 16 of them were asking facilities like cycle and slippers as well as access of drug through the health workers. Most of the subjects need de-addiction service along with TB treatment including nutritional kits, such as,
Table 1: Explore the needs for health care among initial defaulters of tuberculosis treatment $(n=29)$

\begin{tabular}{|c|c|c|c|}
\hline S. no. & Explore the needs for health care & Frequency $(n)$ & Percentage \\
\hline 1 & $\begin{array}{l}\text { Awareness of prevention and } \\
\text { control of tuberculosis including } \\
\text { defaulters and initial defaulters. }\end{array}$ & 08 & 27.5 \\
\hline 2 & $\begin{array}{l}\text { Enforcing the importance } \\
\text { of complete the course of } \\
\text { treatment among new positive } \\
\text { TB patients. }\end{array}$ & 12 & 41.3 \\
\hline 3 & $\begin{array}{l}\text { Providing facilities like cycle and } \\
\text { slippers among new positive TB } \\
\text { patients. }\end{array}$ & 16 & 51.7 \\
\hline 4 & $\begin{array}{l}\text { Drug therapy access to door } \\
\text { level through the health workers } \\
\text { among new positive TB patients. }\end{array}$ & 16 & 51.7 \\
\hline 5 & $\begin{array}{l}\text { Deaddiction services for TB- } \\
\text { positive patients. }\end{array}$ & 21 & 72.4 \\
\hline 6 & $\begin{array}{l}\text { Providing drug kit along with } \\
\text { nutrition kit such as protein- } \\
\text { rich foods like pulses and eggs } \\
\text { (monthly } 15 \text { eggs). }\end{array}$ & 21 & 72.4 \\
\hline 7 & $\begin{array}{l}\text { Provision for technical services } \\
\text { such as SMS alert on drug } \\
\text { therapy. }\end{array}$ & 07 & 25.0 \\
\hline 8 & $\begin{array}{l}\text { Motivation and counseling } \\
\text { services among individual and } \\
\text { family members. }\end{array}$ & 22 & 75.8 \\
\hline 9 & $\begin{array}{l}\text { Encouraging positive support } \\
\text { from the family members on } \\
\text { tuberculosis treatment. }\end{array}$ & 24 & 82.7 \\
\hline
\end{tabular}

pulses and eggs (monthly 15 eggs), 7 of the subjects asking SMS alert for regular drug therapy, 22 initial defaulters asking about family motivation and counseling service, and most of the subjects expecting from their family support toward TB treatment.

\section{Declaration of the Study Participants}

The author has certified that acceptable consent forms have been told that their names and initials will not be released and that proper effort will be made to hide their identity, but anonymity cannot be guaranteed.

\section{References}

1. WHO. Global TB Report No. ISBN 9789241564656. Geneva: World Health Organization, 2013.

2. RNTCP. Technical and Operational guidelines for TB Control. New Delhi: Government of India; 2014.

3. Ministry of Health and Family Welfare, Government of India, Annual status reports; TB India 2014, New Delhi.

4. John TJ, Vashishtha VM, John SM. 50 year of tuberculosis control in India, 2014

5. TB Facts. Org. TB in India: RNTCP, TB Care and Drug Resistant TB. TB factsheets, 2014.

6. Harries $A D$, Rusen ID, Chiang CY, Hinderaker SG, Enarson DA. Registering ID and reporting on their treatment outcome. Int J Tuberc Lung Dis 2009;13(7):801-803.

7. WHO. Standards for TB Care in India. New Delhi: Government of India; 2014. 
8. SaiBabu B, Satyanarayana AV, Venkateshwaralu G, Ramakrishna U, Vikram P, Sahu S, et al. ID among diagnosed sputum smear - positive pulmonary tuberculosis patients in Andhra Pradesh, India. Int J Tuberc Lung Dis 2008;12(9):1055-1058.

9. Gopi PG, Chandrasekaran V, Subramani R, Narayanan PR. Failure to initial treatment for tuberculosis patients diagnosed in a community survey and at health facilities under a DOTS programme in a districts of South India, 2005.

10. Muhammad GM, Ethiraj N. A study of efficiency of referral and compliance of tuberculosis patients in existing network under DOTSA - Cuddalore district, Tamil Nadu, 2013.

11. Mehre D, Kaushik RM, Kaushik R. Initial defaulter among sputum positive pulmonary TB patients at a referral hospital in Uttarakhand India. Trans R Soc Trop Med Hyg 2013;107(9):558-565. DOI: 10.1093/ trstmh/trt065.
12. Munir MK, Iqbal R, Shabbir I, Chaudhry K. Factors responsible for failure to initiate tuberculosis treatment among smear positive pulmonary tuberculosis patients. Pak J Med Res 2012;51(2):34.

13. Korobitsyn A, Bobokhojaev O, Mohr T, Makhmudova M, Trusov A. TB case detection in Tajikistan: analysis of existing obstacles. Cent Asian J Glob Health 2013;2(2):48. DOI: 10.5195/CAJGH.2013.48.

14. Rawat J, Biswas D, Sindhwani G, Kesharwani V, Masih V, Chauhan BS. Diagnostic defaulters: an overlooked aspect in the Indian revised national tuberculosis control program. J Infect Dev Ctries 2012;6(1):20-22. DOI: 10.3855/jidc.1895.

15. Khan MS, Khan S, Godfrey-Fausset P. Default during TB diagnosis: quantifying the problem. Trop Med Int Health 2009;14(12):1437-1441. DOI: $10.1111 /$ j.1365-3156.2009.02406.x.

16. DivijaPillai et al. Study on the Initial Defaulter among Newly Diagnosed TB Patients. Trop Med Res 2015;(2):31. 